\title{
Race Does Not Affect Survival in Patients With Prostate Cancer Treated With Radiation Therapy
}

\author{
JOYSON KODIYAN, MARK ASHAMALLA, ADEL GUIRGUIS and HANI ASHAMALLA
}

Department of Radiation Oncology, New York - Presbyterian Brooklyn Methodist Hospital, New York, NY, U.S.A.

\begin{abstract}
Background/Aim: Recent evidence has shown that African American men with prostate cancer may have more radiosensitive disease with greater overall survival $(O S)$ with radiotherapy compared to Caucasian men. We compared $O S$ in African American and Caucasian men receiving radiotherapy utilizing the National Cancer Database. Patients and Methods: African American or Caucasian men with NOMO prostate adenocarcinoma diagnosed between 2004 and 2013 were selected and grouped into favorable and unfavorable risk based on clinical T-stage, clinical Gleason score, and prostate-specific antigen. Patients with favorable risk received brachytherapy or dose-escalated external beam radiation (EBRT); those with unfavorable risk received EBRT plus anti-androgen therapy with/without brachytherapy. African American and Caucasian men in each subgroup were propensity scorematched and analyzed for survival. Sensitivity analysis used treatment-race and age-race interaction terms. Results: 27,150 patients met the inclusion criteria, with a median age of 68 (range=38-90) years and median follow-up of 59.93 (range=48-142.62) months. OS was equivalent between African American and Caucasian race in favorable risk [logrank $p=0.82$; hazard ratio $(H R)=0.928 ; 95 \%$ confidence intervaI $(C I)=0.583-1.477, p=0.753]$ and unfavorable-risk subgroups (log-rank $p=0.87, H R=1.078,95 \% \quad C I=0.843$ 1.379, $p=0.550$ ). No significant interaction existed between treatment and race for either cohort but there was a significant interaction between race and age in those with unfavorable risk $(H R=1.046, \quad 95 \% \quad C I=1.009-1.084$, $p=0.015)$, with greater $O S$ in those of Caucasian race $\leq 60$ years $\quad(H R=0.320, \quad 95 \% \quad C I=0.137-0.752, \quad p=0.009)$.
\end{abstract}

This article is freely accessible online.

Correspondence to: Joyson Kodiyan, MD, 506 6th Street, Department of Radiation Oncology, New York - Presbyterian Brooklyn Methodist Hospital, Brooklyn, NY 11215, U.S.A. Tel: +1 7187803677, e-mail: jok9122@nyp.org

Key Words: Prostate, radiation, race, survival.
Conclusion: African American and Caucasian men have similar survival when treated with risk-appropriate definitive radiotherapy. However, younger (age $\leq 60$ years) African American men with unfavorable risk have poorer survival than their Caucasian counterparts and may harbor a significantly different biology of disease.

It is commonly held that African American men have more aggressive prostate cancer, with several series demonstrating that African American men were more likely to require treatment from active surveillance compared to Caucasian men $(1,2)$. However, it is debatable whether differences in presentation and disease progression are largely socioeconomically or biologically driven (3).

Notably, significant variations in disease presentation, progression and morbidity between African American and Caucasian men may in part be explained by key genetic differences. Several distinct high-risk chromosomal variations associated with African American men with prostate cancer have been observed in 8q24, 17q21, 17 $\alpha$-hydroxy/17,20-lyase (CYP17), and ten-eleven translocation-2 (TET2) (4-7). Hence, it has been hypothesized that such differences in biology may portend different responses to therapy.

In particular, recent evidence using The Cancer Genome Atlas (TCGA) and tissue samples from four Radiation Therapy Oncology Group (RTOG) trials demonstrated African Americans with prostate cancer have more radiosensitive disease with better distant metastasis and biochemical recurrence-free survival when treated with radiation therapy (8). We investigated whether such a difference in overall survival (OS) exists in a national database between African American and Caucasian men receiving risk-appropriate definitive radiotherapy.

\section{Patients and Methods}

The National Cancer Database was queried for African American or Caucasian men, as defined by the primary race assignment, with prostate adenocarcinoma diagnosed between 2004 and 2013. Patients were excluded if they had node-positive, metastatic or noninvasive disease. A minimum of 4 years of follow-up, measured from the date of diagnosis to death or last follow-up was required. 
Since the only survival endpoint in the database was OS, measured from the date of diagnosis to death from any cause, early events are likely not attributed to prostate cancer given the prolonged natural history of the disease.

Patients were grouped into favorable and unfavorable-risk cohorts based on National Comprehensive Cancer Network risk stratification derived from clinical T-stage, clinical Gleason score, and PSA (9). All analyzed patients had to have received risk-appropriate definitive radiation therapy: Those with favorable risk received brachytherapy (BT) or dose-escalated external beam radiation (EBRT), while those with unfavorable risk received EBRT plus antiandrogen therapy (ADT) with/without BT. Patients receiving EBRT or EBRT plus ADT were to have received at least 7,560 cGy. The cutoff of 7,560 cGy was chosen given the randomized data demonstrating superiority of radiation dose escalation for prostate cancer (10), which is now the standard of care. Patients receiving salvage or adjuvant radiotherapy were excluded.

Statistical considerations. Propensity score analysis was carried out in order to balance confounding covariates including treatment, facility type, facility location, insurance status, income, comorbidities (derived from Charleson-Deyo score) (11), age group, risk group, clinical Tstage, clinical Gleason score, prostate-specific antigen (prostatespecific antigen), and whether treatment started within 90 days.

Two groups were then created based on risk (favorable or unfavorable). African American and Caucasian men in each group were matched using calculated propensity scores. Multivariate analysis was carried out on both unmatched and matched cohorts, and subgroup analysis on the matched cohorts. Covariates in the multivariate analysis were selected a priori and included clinically and socioeconomically meaningful variables including radiation treatment modality, race, facility type, facility location, insurance status, income, comorbidities, age, treatment start time, risk group, clinical T-score, clinical Gleason score, and PSA.

In order to analyze whether BT-containing therapy had a different impact on survival based on race, sensitivity analysis was conducted using a treatment-race interaction term. Additionally, a second sensitivity analysis was performed using an age-race interaction term given the strong evidence that earlier onset prostate cancer is a significantly different disease entity from older onset prostate cancer (12), and hence may show a differential response to radiation.

Survival analysis consisted of Kaplan-Meier statistics and Cox proportional hazard regression models. All propensity scorematched (PSM) models were well balanced with covariate standardized mean differences $<10 \%$, and all Cox multivariate models were evaluated for the proportional hazards assumption using Schoenfeld residuals. Two-sided p-values were utilized using a significance level of 0.05 . Statistical analysis was completed using $\mathrm{R}$ version 3.5.1.

\section{Results}

Of $1,294,126$ patients identified, 27,150 met the inclusion criteria (Figure 1), with a median age of 68 (range $=38-90)$ years and median follow-up of 59.93 (range $=48-142.62$ ) months.

In the unmatched favorable-risk group $(n=13,870)$, no significant survival difference was seen between African American and Caucasian race (Figure 2A). A total of 2,688 cases were matched (Table I). Seventy percent $(n=1878)$ of patients were at low risk, with nearly all having PSA $<10 \mathrm{ng} / \mathrm{ml}$ $(\mathrm{n}=2,655 ; 99 \%)$ and most having clinical Gleason score $\leq 6$ $(\mathrm{n}=1,900 ; 71 \%)$. There was no significant difference in OS between African American and Caucasian men in this matched cohort (HR=0.928, 95\% CI=0.583-1.477, $p=0.753$ ). Subgroup analysis based on clinical or pathological variables demonstrated no significant survival differences (Figure 3). Sensitivity analysis revealed no significant interactions between race and treatment (Table II) or race and age (Table IV).

Among the patients of the unfavorable-risk group $(\mathrm{n}=13,280)$, no significant survival difference was seen between African American and Caucasian race (Figure 2B). A total of 1,468 cases were matched (Table III). Most were at high risk $(\mathrm{n}=1,317 ; 90 \%)$ with PSA $>20 \mathrm{ng} / \mathrm{ml}(\mathrm{n}=1,141 ; 78 \%)$. African American and Caucasian men had no significant difference in OS (hazard ratio $=0.972,95 \%$ confidence intervaI $=0.765-1.236$, $p=0.819)$. Subgroup analysis demonstrated Caucasian race was a predictor for greater OS in the cohort aged $\leq 60$ years (HR=0.320, 95\% CI=0.137-0.752, $p=0.009$ ) (Figure 4). Sensitivity analysis demonstrated no significant interaction between race and treatment (Table II), but did demonstrate a significant interaction between race and age $(\mathrm{HR}=1.046,95 \%$ $\mathrm{CI}=1.009-1.084, \mathrm{p}=0.015)$ (Table IV).

\section{Discussion}

No survival difference was observed between African American and Caucasian men in both the favorable risk cohort receiving radiation (BT or EBRT) and the unfavorable risk cohort receiving radiation (EBRT plus ADT or EBRT plus BT and ADT). BT-containing therapy, either BT monotherapy for favorable risk or BT boost in unfavorable risk, did not significantly differ in race-specific survival. In the favorablerisk group, multivariate analysis demonstrated that radiation modality did not significantly influence survival, while EBRT plus BT and ADT conferred a significant survival advantage, regardless of race (Table II).

The lack of survival difference between African American and Caucasian men in our study is consistent with several smaller retrospective studies (13-17). One series of 2,301 patients (270 African Americans) receiving BT-containing therapy across all risk groups demonstrated no significant difference in OS between African American and Caucasian race, with comparable biochemical disease-free survival in the intermediate- and high-risk groups (11). Similarly, in a series from Memorial Sloan Kettering of 1,081 patients (246 African Americans) receiving BT-containing therapy, no significant difference in biochemical disease-free survival was observed at 5 years between African American and Caucasian men in risk- matched cohorts (14). In a retrospective study of four randomized trials from 1975 to 1992, which included 191 African Americans, no OS or disease-specific survival differences were seen between African American and 


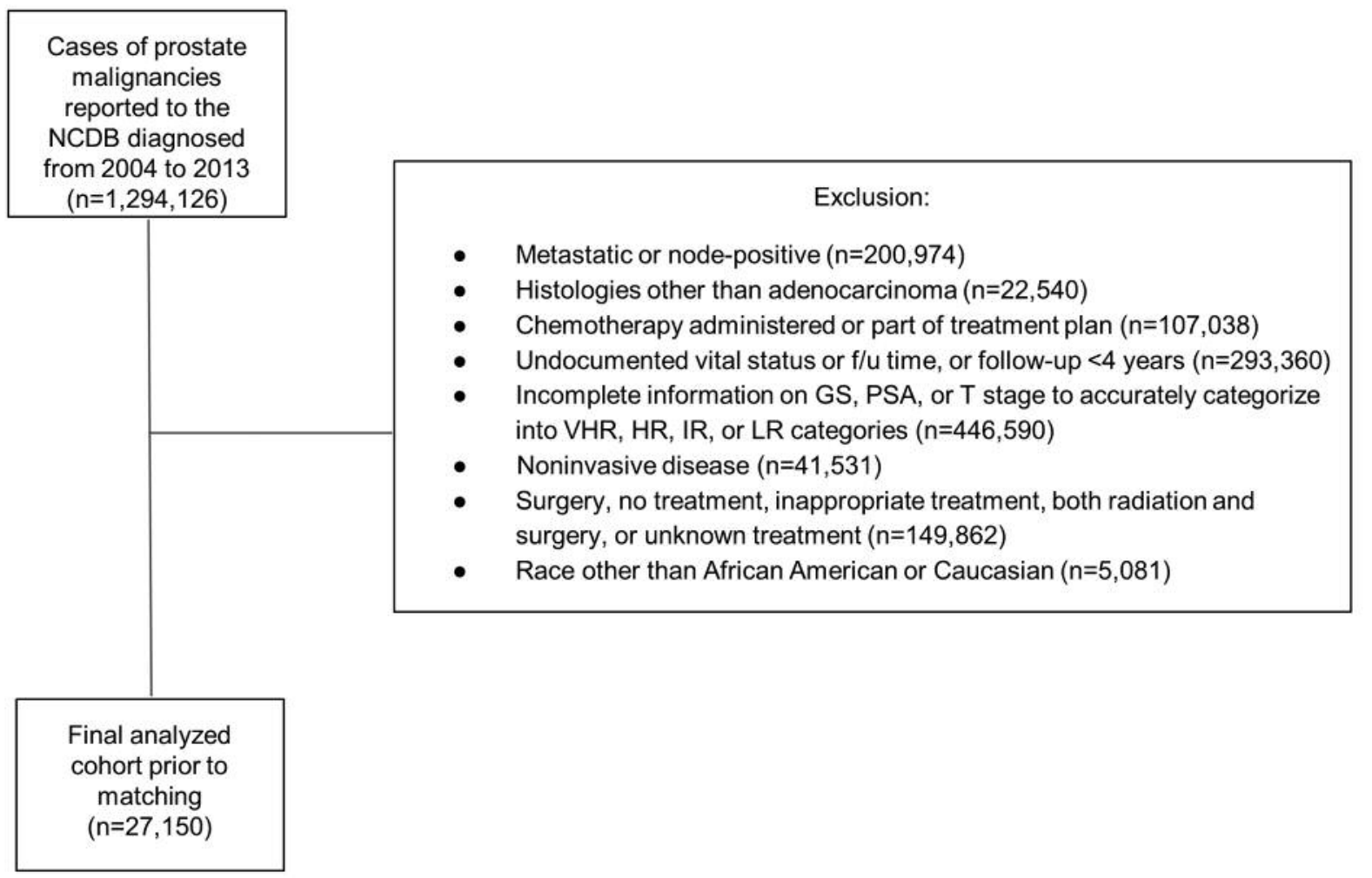

Figure 1. CONSORT diagram. GS: Gleason score; HR: high risk; LR: low risk; NCDB: National Cancer Database; PSA: prostate-specific antigen; IR: intermediate risk; RT: radiation therapy; VHR: very high risk.
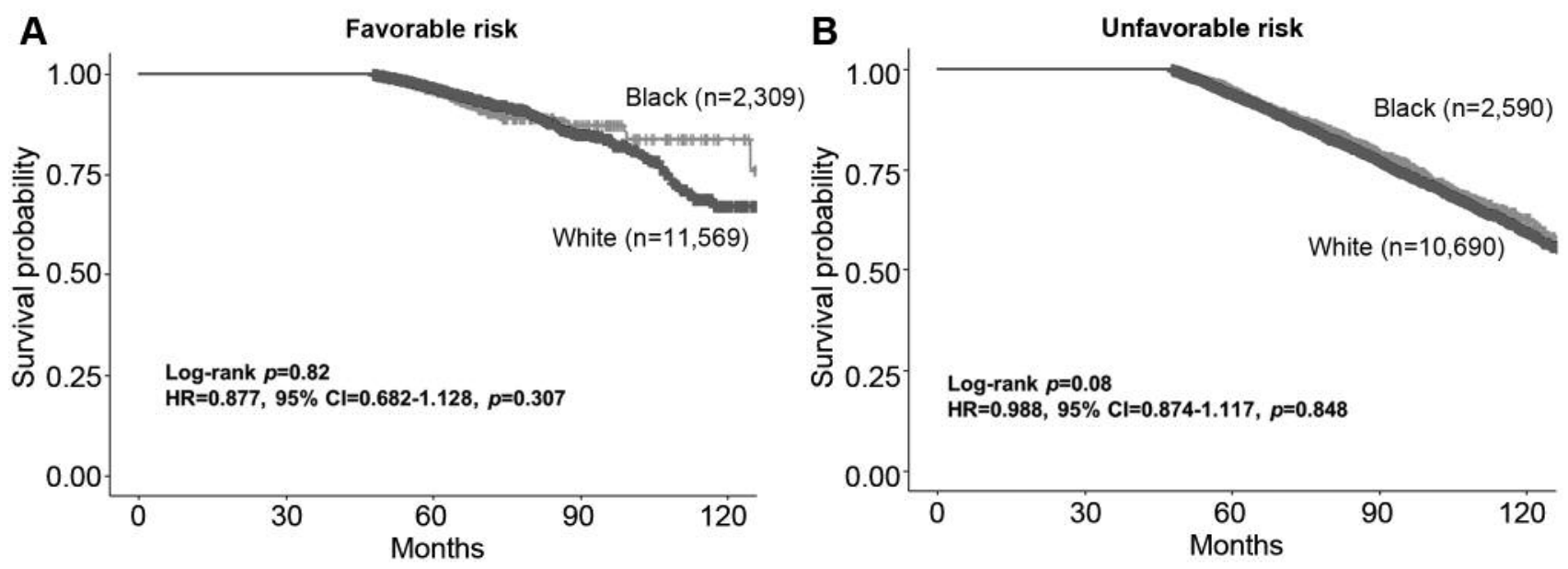

Figure 2. Kaplan-Meier curves comparing survival between African Americans (AfAs) and Caucasians (Ccs) in favorable (A) and unfavorable (B) risk cohorts. HR: Hazard ratio; CI: confidence interval.

Caucasian men receiving EBRT with/without ADT (12). In contrast to many of the aforementioned studies, a significant strength of our study is the large number of African Americans $(n=4,818)$ in the database that were investigated, as well as the inclusion of only modern treatment regimens, particularly excluding any patient that did not receive dose-escalated EBRT (at least 7,560 cGy), and excluding those high-risk patients who did not receive ADT with EBRT. 
Table I. Patient baseline characteristics in the matched, favorable-risk cohort according to race.

\begin{tabular}{|c|c|c|c|c|c|}
\hline & & \multicolumn{2}{|c|}{ Race, n (\%) } & \multirow[b]{2}{*}{$p$-Value } & \multirow[b]{2}{*}{ SMD } \\
\hline & & $\begin{array}{c}\text { African American } \\
\mathrm{N}=1344\end{array}$ & $\begin{array}{c}\text { Caucasian } \\
\mathrm{N}=1344\end{array}$ & & \\
\hline Age, years & Mean \pm SD & $64.55 \pm 6.73$ & $64.77 \pm 6.80$ & 0.386 & 0.033 \\
\hline \multirow[t]{2}{*}{ Treatment } & BT & $757(52.3)$ & $706(52.5)$ & 0.053 & 0.076 \\
\hline & EBRT & $587(43.7)$ & $638(47.5)$ & & \\
\hline \multirow[t]{2}{*}{ Facility type } & Academic & $620(46.1)$ & $569(42.3)$ & 0.052 & 0.076 \\
\hline & Community & $724(53.9)$ & $775(57.7)$ & & \\
\hline \multirow[t]{4}{*}{ Facility location } & Midwest & $220(16.4)$ & $238(17.7)$ & 0.225 & 0.081 \\
\hline & Northeast & $243(18.1)$ & $217(16.1)$ & & \\
\hline & South & $813(60.5)$ & $836(62.2)$ & & \\
\hline & West & $68(5.1)$ & $53(3.9)$ & & \\
\hline \multirow[t]{3}{*}{ Diagnosis to treatment start } & 0-90 Days & $655(48.7)$ & $660(49.1)$ & 0.709 & 0.032 \\
\hline & >90 Days & $675(50.2)$ & $674(50.1)$ & & \\
\hline & Unknown & $14(1.0)$ & $10(0.7)$ & & \\
\hline \multirow[t]{2}{*}{ Insurance status } & Insured & $1339(99.6)$ & $1340(99.7)$ & 1.000 & 0.013 \\
\hline & Uninsured & $5(0.4)$ & $4(0.3)$ & & \\
\hline \multirow[t]{3}{*}{ Median income } & $<38,000 \$$ & $317(23.6)$ & $321(23.9)$ & 0.598 & 0.039 \\
\hline & $\geq 38,000 \$$ & $1026(76.3)$ & $1023(76.1)$ & & \\
\hline & Unknown & $1(0.1)$ & $0(0.0)$ & & \\
\hline \multirow[t]{2}{*}{ Comorbidities } & Absent & $1206(89.7)$ & $1222(90.9)$ & 0.328 & 0.040 \\
\hline & Present & $138(10.3)$ & $122(9.1)$ & & \\
\hline \multirow[t]{2}{*}{ Risk group } & Low & $946(70.4)$ & $932(69.3)$ & 0.585 & 0.023 \\
\hline & Favorable intermediate & $398(29.6)$ & $412(30.7)$ & & \\
\hline \multirow[t]{2}{*}{$\mathrm{PSA}, \mathrm{ngl} / \mathrm{ml}^{*}$} & $\leq 10$ & $1329(98.9)$ & $1326(98.7)$ & 0.726 & 0.020 \\
\hline & $10-20$ & $15(1.1)$ & $18(1.3)$ & & \\
\hline \multirow[t]{2}{*}{ Gleason score $^{\dagger}$} & $\leq 6$ & $957(71.2)$ & $943(70.2)$ & 0.582 & 0.023 \\
\hline & $7(3+4)$ & $387(28.8)$ & $401(29.8)$ & & \\
\hline \multirow[t]{2}{*}{ T-Stage } & $\mathrm{T} 1$ & $1240(92.3)$ & $1222(90.9)$ & 0.237 & 0.048 \\
\hline & $\mathrm{T} 2$ & $104(7.7)$ & $122(9.1)$ & & \\
\hline
\end{tabular}

BT: Brachytherapy; EBRT: external beam radiation therapy; ADT: androgen deprivation therapy; SMD: standardized mean difference; CI: confidence interval; ${ }^{\dagger}$ combined score.

Table II. Hazard ratios (HR) and confidence intervaIs (CI) for death in propensity score-matched favorable- and unfavorable-risk cohorts according to race and treatment, with treatment modality interaction term*.

\begin{tabular}{|c|c|c|c|c|c|c|}
\hline \multirow[b]{2}{*}{ Variable } & \multicolumn{3}{|c|}{ Favorable risk } & \multicolumn{3}{|c|}{ Unfavorable risk } \\
\hline & & HR $(95 \% \mathrm{CI})$ & $p$-Value & & HR $(95 \% \mathrm{CI})$ & $p$-Value \\
\hline \multirow[t]{2}{*}{ Race } & African American & Reference & & African American & Reference & \\
\hline & Caucasian & $0.636(0.309-1.311)$ & 0.22 & Caucasian & $0.9545(0.742-1.227)$ & 0.714 \\
\hline \multirow[t]{2}{*}{ Treatment } & $\mathrm{BT}$ & Reference & & $\mathrm{EBRT}+\mathrm{ADT}$ & Reference & \\
\hline & EBRT & $1.136(0.580-2.224)$ & 0.711 & $\mathrm{EBRT}+\mathrm{BT}+\mathrm{ADT}$ & $0.491(0.255-0.944)$ & 0.033 \\
\hline Race $\times$ Treatment & & $1.983(0.755-5.209)$ & 0.165 & & $1.246(0.525-2.956)$ & 0.618 \\
\hline
\end{tabular}

BT: Brachytherapy; EBRT: external beam radiation therapy; ADT: androgen deprivation therapy. *Controlled for socioeconomic factors, age, comorbidity, risk, clinical Gleason, prostate-specific antigen, clinical T-stage, and treatment delay.

A notable finding of our study is the significant interaction of race with age for the unfavorable-risk group (Table IV). Subgroup analysis of the younger (age $\leq 60$ years) unfavorable risk cohort demonstrated that Caucasian race was a significant predictor for improved OS. Our findings suggest that young African American men with unfavorablerisk prostate cancer may have a significantly more aggressive disease entity portending a worse OS than that of Caucasian men in the same age category, which is not seen in the older cohort, nor in those with favorable risk disease. Furthermore, 
Table III. Patient baseline characteristics in the matched, unfavorable-risk cohort according to race.

\begin{tabular}{|c|c|c|c|c|c|}
\hline \multirow[t]{2}{*}{ Race } & & \multicolumn{2}{|c|}{ Race, n (\%) } & \multirow[b]{2}{*}{$p$-Value } & \multirow[b]{2}{*}{ SMD } \\
\hline & & $\begin{array}{c}\text { African American } \\
\qquad \mathrm{N}=734\end{array}$ & $\begin{array}{c}\text { Caucasian } \\
\mathrm{N}=734\end{array}$ & & \\
\hline Age, years & Mean \pm SD & $68.02 \pm 6.88$ & $68.03 \pm 6.88$ & 0.984 & 0.001 \\
\hline \multirow[t]{4}{*}{ Treatment } & $\mathrm{EBRT}+\mathrm{ADT}$ & $651(98.7)$ & $646(88)$ & 0.745 & 0.021 \\
\hline & $\mathrm{EBRT}+\mathrm{BT}+\mathrm{ADT}$ & $83(11.3)$ & $88(12.0)$ & & \\
\hline & Academic & $275(37.5)$ & $279(38.0)$ & 0.872 & 0.011 \\
\hline & Community & $459(62.5)$ & $455(62.0)$ & & \\
\hline \multirow[t]{4}{*}{ Facility Location } & Midwest & $136(18.5)$ & $135(18.4)$ & 0.999 & 0.007 \\
\hline & Northeast & $161(21.9)$ & $163(22.2)$ & & \\
\hline & South & $391(53.3)$ & $390(53.1)$ & & \\
\hline & West & $46(6.3)$ & $46(6.3)$ & & \\
\hline \multirow[t]{3}{*}{ Diagnosis to treatment start } & 0-90 Days & $660(89.9)$ & $657(89.5)$ & 0.967 & 0.013 \\
\hline & $>90$ Days & $49(6.7)$ & $51(6.9)$ & & \\
\hline & Unknown & $25(3.4)$ & $26(3.5)$ & & \\
\hline \multirow[t]{2}{*}{ Insurance status } & Insured & $733(99.9)$ & $733(99.9)$ & $>0.999$ & $<0.001$ \\
\hline & Uninsured & $1(0.1)$ & $1(0.1)$ & & \\
\hline \multirow[t]{3}{*}{ Median income } & $<38,000 \$$ & $147(20.0)$ & $147(20.0)$ & 0.846 & 0.030 \\
\hline & $\geq 38,000 \$$ & $586(79.8)$ & $585(79.7)$ & & \\
\hline & Unknown & $1(0.1)$ & $2(0.3)$ & & \\
\hline \multirow[t]{2}{*}{ Comorbidities } & Absent & $702(95.6)$ & $699(95.2)$ & 0.802 & 0.020 \\
\hline & Present & $32(4.4)$ & $35(4.8)$ & & \\
\hline \multirow[t]{3}{*}{ Risk group } & Unfavorable intermediate & $44(6.0)$ & $44(6.0)$ & 0.992 & 0.007 \\
\hline & High & $659(89.8)$ & $658(89.6)$ & & \\
\hline & Very high & $31(4.2)$ & $32(4.4)$ & & \\
\hline \multirow[t]{3}{*}{$\mathrm{PSA}, \mathrm{ngl} / \mathrm{ml}$} & $<10$ & $115(15.7)$ & $120(16.3)$ & 0.710 & 0.061 \\
\hline & $10-20$ & $48(6.5)$ & $43(5.9)$ & & \\
\hline & $>20$ & $571(77.8)$ & $570(77.7)$ & & \\
\hline \multirow[t]{6}{*}{ Gleason score $\dagger$} & $\leq 6$ & $4(0.5)$ & $5(0.7)$ & 0.999 & 0.025 \\
\hline & 7 & $72(9.8)$ & $74(10.1)$ & & \\
\hline & 8 & $72(9.8)$ & $73(9.9)$ & & \\
\hline & 9 & $24(3.3)$ & $22(3.0)$ & & \\
\hline & 10 & $1(0.1)$ & $1(0.1)$ & & \\
\hline & Unknown & $561(76.4)$ & $559(76.2)$ & & \\
\hline \multirow[t]{5}{*}{ T-Stage } & $\mathrm{T} 1$ & $387(52.7)$ & $384(52.3)$ & 0.837 & 0.063 \\
\hline & $\mathrm{T} 2$ & $264(36.0)$ & $263(35.8)$ & & \\
\hline & $\mathrm{T} 3$ & $81(11.0)$ & $85(11.6)$ & & \\
\hline & $\mathrm{T} 4$ & $2(0.3)$ & $1(0.1)$ & & \\
\hline & Tx & $0(0.0)$ & $1(0.1)$ & & \\
\hline
\end{tabular}

BT: Brachytherapy; EBRT: external beam radiation therapy; ADT: androgen deprivation therapy; SMD: standardized mean difference; CI: confidence interval; ${ }^{\dagger}$ combined score.

this finding is consistent with prior evidence showing that prostate cancer of younger patients is a biologically different entity with greater likelihood for genetic etiology (10).

Although African American men may have more aggressive prostate cancer compared to their Caucasian counterparts, their similar survival on treatment with definitive radiotherapy may be due to a different gene-expression profile compared to that of Caucasian men, making their disease more sensitive to radiation (7-9, 18-21). Significant differences in genomic expression have already been established, including CYP17 polymorphisms, high risk TET2 variants, $8 \mathrm{q} 24$ variants, and $17 q 21$ variants $(4,7,21)$. One study created four prognostic genomic subgroups (gain of chromosome 7 , deletion of
$8 \mathrm{p} /$ gain of $8 \mathrm{q}$, loss of $8 \mathrm{p}$ and $16 \mathrm{q}$, and quiet genome) which successfully stratified outcomes of patients undergoing definitive surgery or radiation therapy (19). Another study of cases from two randomized trials found that specific markers for tumor hypoxia and angiogenesis, particularly expression of vascular endothelial growth factor and hypoxia-induciblefactor-alpha, were negative prognosticators in those undergoing radiation or surgery, but osteopontin expression was a negative prognosticator for those undergoing surgery but not radiation, thus highlighting different responses to treatment modalities based on the biology of the disease (20).

Recent evidence has shown that African American men may even do better than Caucasian men with radiation therapy. 


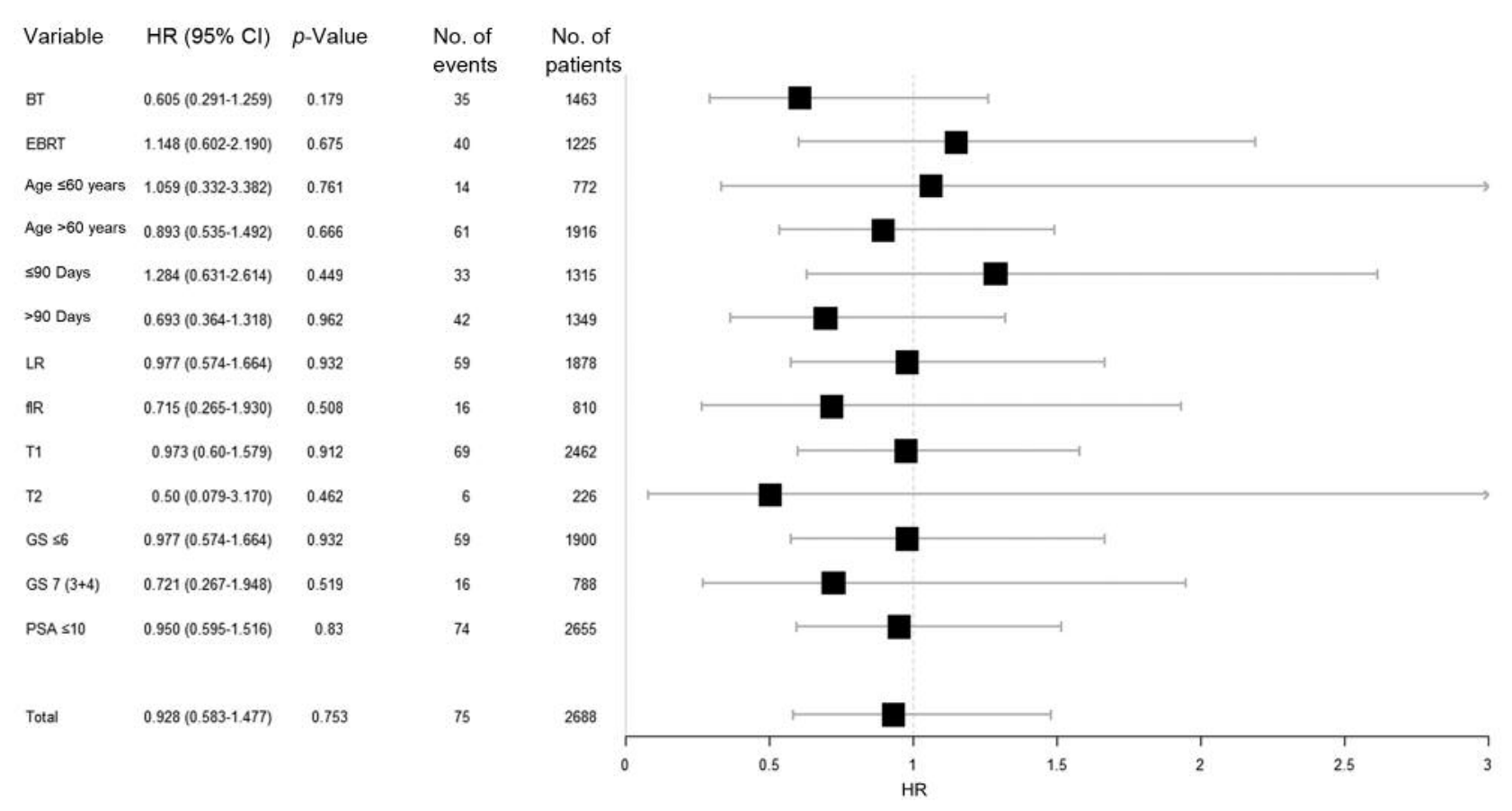

Figure 3. Subgroup analysis forest plot of hazard ratios (HR) and confidence intervals (CI) in African Americans (AfAs) and Caucasians (Ccs) with favorable risk. HR greater than 1 favors African American race. BT: Brachytherapy; EBRT: external beam radiotherapy; LR: low risk; fIR: favorable intermediate risk; GS: Gleason score; PSA: prostate-specific antigen.

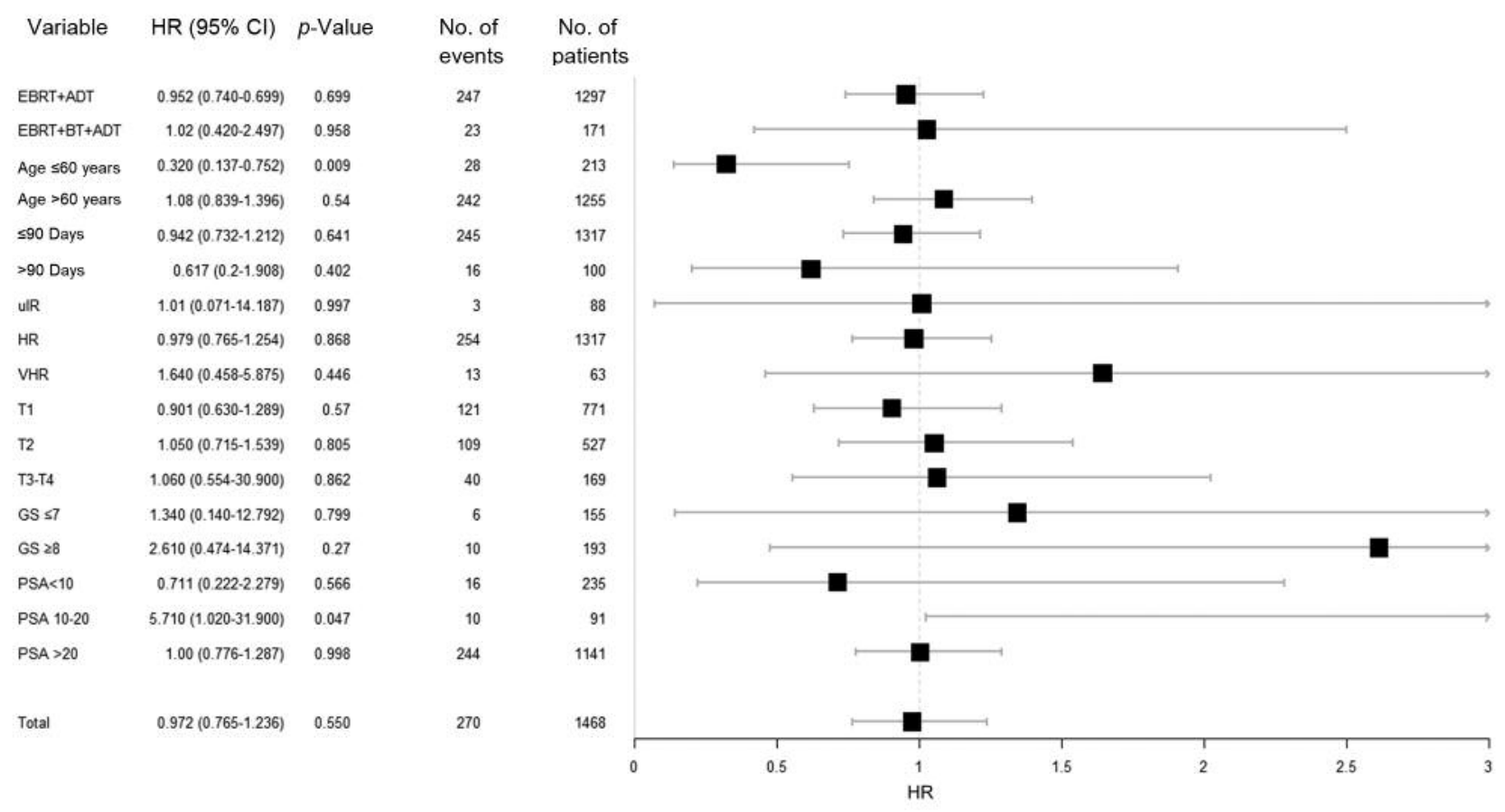

Figure 4. Subgroup analysis forest plot of hazard ratios (HR) and confidence intervals (CI) in African Americans (AfAs) and Caucasians (Ccs) with unfavorable risk. HR greater than 1 favors African American race. BT: Brachytherapy; EBRT: external beam radiotherapy; uIR: unfavorable intermediate risk; HR: high risk; VHR: very high risk; GS: Gleason score; PSA: prostate-specific antigen. 
Table IV. Hazard ratios (HR) and confidence intervals (CIs) for death in propensity score-matched favorable- and unfavorable-risk cohorts according to race and age, with age interaction term*.

\begin{tabular}{|c|c|c|c|c|c|}
\hline \multirow[b]{2}{*}{ Variable } & & \multicolumn{2}{|c|}{ Favorable risk } & \multicolumn{2}{|c|}{ Unfavorable risk } \\
\hline & & HR $(95 \%$ CI $)$ & $p$-Value & HR $(95 \%$ CI $)$ & $p$-Value \\
\hline \multirow[t]{2}{*}{ Race } & African American & Reference & & Reference & \\
\hline & Caucasian & $1.031(0.630-1.687)$ & 0.905 & $0.917(0.716-1.174)$ & 0.493 \\
\hline Age & & $1.032(0.978-1.088)$ & 0.248 & $1.015(0.989-1.041)$ & 0.258 \\
\hline Race $\times$ Age & & $0.956(0.975-1.121)$ & 0.208 & $1.046(1.009-1.084)$ & 0.015 \\
\hline
\end{tabular}

*Controlled for socioeconomic factors, comorbidity, risk, clinical Gleason, prostate-specific antigen, clinical T-stage, and treatment delay.

Using a scale to predict radiotherapy response called the PORTOS (a 24-gene Post-Operative Radiation Therapy Outcomes Score) (18), Spratt et al. demonstrated that African American men had a higher PORTOS score than Caucasian men, which was clinically validated using patients receiving radiation from four RTOG trials (18.5\% African American race); PSM multivariate analysis demonstrated African American race predicted improved biochemical recurrence $(\mathrm{HR}=0.82,95 \% \mathrm{CI}=0.74-0.92, p<0.001)$ and $\mathrm{DM}$ rates $(\mathrm{HR}=0.7,95 \% \mathrm{CI}=0.57-0.86, p<0.001)(8)$. Genomic risk stratification of prostate cancer appears to have great potential compared to the current NCCN risk stratification and may allow for better tailoring of treatment options. Unfortunately, many of the large genomic studies under-represented African Americans and over-represented Caucasians, consequently having inadequate power to detect mutational frequency rates in African Americans with prostate cancer, hence making it difficult to stratify risk better and prognosticate their disease compared to that of Caucasians $(22,23)$.

Our major limitation is due to the retrospective nature of our study. We attempted to control selection bias and influential covariates by using PSM analysis. However, without randomization, there will always be undefined covariates that may explain the absence of survival differences. In addition, the database is limited to OS data only, yet there may be a significant influence of competing risks which may play a significant role in the observed survival rates. Additionally, PSM analysis inherently selects a subgroup of the total population in an attempt to reduce confounding. However, in doing so, the selected sample may not accurately represent the general population; although all matched cohorts were well-balanced in all selected covariates, the majority of matched patients had no comorbidities, were insured and had income $\geq 38,000 \$$.

\section{Conclusion}

No difference in survival was observed between African American and Caucasian men when treated with risk- appropriate definitive radiotherapy. However, younger (age $\leq 60$ years) African American men with unfavorable risk have poorer survival than their Caucasian counterparts and may harbor a significantly different biology of disease.

\section{Conflicts of Interest}

All Authors listed contributed sufficiently to the project to be included as authors, and all those who are qualified to be authors are listed in the author byline. To the best of our knowledge, no conflict of interest, financial or other, exists. No specific funding was received for this work.

\section{Authors' Contributions}

Joyson Kodiyan: Writing, methodology, statistical design, reviewing, editing. Mark Ashamalla: reviewing, editing. Adel Guirguis: data acquisition, statistical design. Hani Ashamalla: supervision, conceptualization, methodology, reviewing, editing.

\section{References}

1 Abern MR, Bassett MR, Tsivian M, Bañez LL, Polascik TJ, Ferrandino MN, Robertson CN, Freedland SJ and Moul JW: Race is associated with discontinuation of active surveillance of low-risk prostate cancer: Results from the Duke Prostate Center. Prostate Cancer Prostatic Dis 16: 85-90, 2013. PMID: 23069729. DOI: $10.1038 /$ pcan.2012.38.

2 Iremashvili V, Soloway MS, Rosenberg DL and Manoharan M: Clinical and demographic characteristics associated with prostate cancer progression in patients on active surveillance. J Urol 187: 1594-1600, 2012. PMID: 22425088. DOI: 10.1016/j.juro.2011. 12.082

3 Chornokur G, Dalton K, Borysova ME and Kumar NB: Disparities at presentation, diagnosis, treatment, and survival in African American men, affected by prostate cancer. Prostate 71: 985-997, 2011. PMID: 21541975. DOI: 10.1002/pros.21314

4 Koboldt DC, Kanchi KL, Gui B, Larson DE, Fulton RS, Isaacs WB, Kraja A, Borecki IB, Jia L, Wilson RK, Mardis ER and Kibel AS: Rare variation in TET2 is associated with clinically relevant prostate carcinoma in African Americans. Cancer Epidemiol Biomarkers Prev 25: 1456-1463, 2016. PMID: 27486019. DOI: 10.1158/1055-9965.EPI-16-0373 
5 Taioli E, Sears V, Watson A, Flores-Obando RE, Jackson MD, Ukoli FA, de Syllos Cólus IM, Fernandez P, McFarlane-Anderson N, Ostrander EA, Rodrigues IS, Stanford JL, Taylor JA, TullochReid M and Ragin CCR: Polymorphisms in CYP17 and CYP3A4 and prostate cancer in men of African descent. Prostate 73: 668676, 2013. PMID: 23129512. DOI: 10.1002/pros.22612

6 Haiman CA, Chen GK, Blot WJ, Strom SS, Berndt SI, Kittles RA, Rybicki BA, Isaacs WB, Ingles SA, Stanford JL, Ryan Diver W, Witte JS, Hsing AW, Nemesure B, Rebbeck TR, Cooney KA, Xu J, Kibel AS, Hu JJ, John EM, Gueye SM, Watya S, Signorello LB, Hayes RB, Wang Z, Yeboah E, Tettey Y, Cai Q, Kolb S, Ostrander EA, Zeigler-Johnson C, Yamamura Y, Neslund-Dudas C, HaslagMinoff J, Wu W, Thomas V, Allen GO, Murphy A, Chang B-L, Lilly Zheng S, Cristina Leske M, Wu S-Y, Ray AM, Hennis AJM, Thun MJ, Carpten J, Casey G, Carter EN, Duarte ER, Xia LY, Sheng X, Wan P, Pooler LC, Cheng I, Monroe KR, Schumacher F, Le Marchand L, Kolonel LN, Chanock SJ, Van Den Berg D, Stram DO and Henderson BE: Genome-wide association study of prostate cancer in men of African ancestry identifies a susceptibility locus at 17q21. Nat Genet 43: 570-573, 2011. PMID: 21602798. DOI: $10.1038 /$ ng.839

7 Freedman ML, Haiman CA, Patterson N, McDonald GJ, Tandon A, Waliszewska A, Penney K, Steen RG, Ardlie K, John EM, Oakley-Girvan I, Whittemore AS, Cooney KA, Ingles SA, Altshuler D, Henderson BE and Reich D: Admixture mapping identifies $8 \mathrm{q} 24$ as a prostate cancer risk locus in AfricanAmerican men. Proc Natl Acad Sci USA 103: 14068-14073, 2006. PMID: 16945910. DOI: 10.1073/pnas.0605832103

8 Spratt DE, Dess RT, Hartman HE, Mahal BA, Jackson WC, Soni PD, Alshalalfa M, Fishbane N, Zumsteg ZS, Shipley WU, Pisansky TM, Roach M, Zhao SG, Speers C, Davicioni E, Schipper M, Nguyen PL, Schaeffer EM, Feng FY and Sandler HM: Androgen receptor activity and radiotherapeutic sensitivity in africanamerican men with prostate cancer: A large scale gene expression analysis and meta-analysis of RTOG trials. Int J Radiat Oncol Biol Phys 102: S3, 2018. DOI: 10.1016/j.ijrobp.2018.06.104

9 Mohler JL and Antonarakis ES: NCCN guidelines updates: Management of prostate cancer. J Natl Compr Canc Netw 17: 583-586, 2019. DOI: 10.6004/jncen.2019.5011

10 Hou Z, Li G and Bai S: High dose versus conventional dose in external beam radiotherapy of prostate cancer: a meta-analysis of long-term follow-up. J Cancer Res Clin Oncol 141: 1063-1071, 2015. PMID: 25173623. DOI: 10.1007/s00432-014-1813-1

11 Sundararajan V, Henderson T, Perry C, Muggivan A, Quan H and Ghali WA: New ICD-10 version of the Charlson comorbidity index predicted in-hospital mortality. J Clin Epidemiol 57: 1288-1294, 2004. PMID: 15617955. DOI: 10.1016/j.jclinepi.2004.03.012

12 Salinas CA, Tsodikov A, Ishak-Howard M and Cooney KA: Prostate cancer in young men: an important clinical entity. Nat Rev Urol 11: 317-323, 2014. PMID: 24818853. DOI: 10.1038/nrurol.2014.91

13 Yamoah K, Stone N and Stock R: Impact of race on biochemical disease recurrence after prostate brachytherapy. Cancer 117: 5589-5600, 2011. PMID: 21692058. DOI: 10.1002/cncr.26183

14 Roach M 3rd, Lu J, Pilepich MV, Asbell SO, Mohiuddin M and Grignon D: Race and survival of men treated for prostate cancer on radiation therapy oncology group phase III randomized trials. J Urol 169: 245-250, 2003. PMID: 12478146. DOI: 10.1097/01.ju.0000041412.57484.cd
15 Sohayda CJ, Kupelian PA, Altsman KA and Klein EA: R Race as an independent predictor of outcome after treatment for localized prostate cancer. J Urol 162(4): 1331-1336, 1999. PMID: 10492191.

16 Lee LN, Barnswell C, Torre T, Fearn P, Kattan M and Potters L: Prognostic significance of race on biochemical control in patients with localized prostate cancer treated with permanent brachytherapy: multivariate and matched-pair analyses. Int $\mathbf{J}$ Radiat Oncol Biol Phys 53: 282-289, 2002. PMID: 12023131. DOI: $10.1016 / \mathrm{s} 0360-3016(02) 02747-5$

17 Zagars GK, Pollack A and Pettaway CA: Prostate cancer in AfricanAmerican men: outcome following radiation therapy with or without adjuvant androgen ablation. Int J Radiat Oncol Biol Phys 42: 517523, 1998. PMID: 9806509. DOI: 10.1016/s0360-3016(98)00260-0

18 Zhao SG, Chang SL, Spratt DE, Erho N, Yu M, Ashab HA-D, Alshalalfa M, Speers C, Tomlins SA, Davicioni E, Dicker AP, Carroll PR, Cooperberg MR, Freedland SJ, Karnes RJ, Ross AE, Schaeffer EM, Den RB, Nguyen PL and Feng FY: Development and validation of a 24-gene predictor of response to postoperative radiotherapy in prostate cancer: a matched, retrospective analysis. Lancet Oncol 17: 1612-1620, 2016. PMID: 27743920. DOI: 10.1016/S1470-2045(16)30491-0

19 Lalonde E, Ishkanian AS, Sykes J, Fraser M, Ross-Adams H, Erho N, Dunning MJ, Halim S, Lamb AD, Moon NC, Zafarana G, Warren AY, Meng X, Thoms J, Grzadkowski MR, Berlin A, Have CL, Ramnarine VR, Yao CQ, Malloff CA, Lam LL, Xie H, Harding NJ, Mak DYF, Chu KC, Chong LC, Sendorek DH, P'ng C, Collins CC, Squire JA, Jurisica I, Cooper C, Eeles R, Pintilie M, Dal Pra A, Davicioni E, Lam WL, Milosevic M, Neal DE, van der Kwast T, Boutros PC and Bristow RG: Tumour genomic and microenvironmental heterogeneity for integrated prediction of 5-year biochemical recurrence of prostate cancer: a retrospective cohort study. Lancet Oncol 15: 1521-1532, 2014. PMID: 25456371. DOI: 10.1016/S1470-2045(14)71021-6

20 Vergis R, Corbishley CM, Norman AR, Bartlett J, Jhavar S, Borre M, Heeboll S, Horwich A, Huddart R, Khoo V, Eeles R, Cooper C, Sydes M, Dearnaley D and Parker C: Intrinsic markers of tumour hypoxia and angiogenesis in localised prostate cancer and outcome of radical treatment: a retrospective analysis of two randomised radiotherapy trials and one surgical cohort study. Lancet Oncol 9: 342-351, 2008. PMID: 18343725. DOI: $10.1016 / \mathrm{S} 1470-2045(08) 70076-7$

21 Haiman CA, Patterson N, Freedman ML, Myers SR, Pike MC, Waliszewska A, Neubauer J, Tandon A, Schirmer C, McDonald GJ, Greenway SC, Stram DO, Le Marchand L, Kolonel LN, Frasco M, Wong D, Pooler LC, Ardlie K, Oakley-Girvan I, Whittemore AS, Cooney KA, John EM, Ingles SA, Altshuler D, Henderson BE and Reich D: Multiple regions within 8q24 independently affect risk for prostate cancer. Nat Genet 39: 638644, 2007. PMID: 17401364. DOI: $10.1038 / n g 2015$

22 Spratt DE, Chan T, Waldron L, Speers C, Feng FY, Ogunwobi OO and Osborne JR: Racial/ethnic disparities in genomic sequencing. JAMA Oncol 2: 1070-1074, 2016. PMID: 27366979. DOI: $10.1001 /$ jamaoncol.2016.1854

23 Tan S-H, Petrovics G and Srivastava S: Prostate Cancer Genomics: Recent advances and the prevailing underrepresentation from racial and ethnic minorities. Int J Mol Sci 19, 2018. PMID: 2969056. DOI: $10.3390 /$ ijms 19041255

Received April 24, 2020

Revised May 13, 2020

Accepted May 16, 2020 